\title{
Uma reflexão sobre o componente ilógico do brincar - experiência estética... mobílias mutantes nos arranjos do vivido
}

\author{
Marlon Dantas Trevisan
}

Resumo: O presente trabalho se inspirou na observação de crianças de quatro anos brincando em um laboratório de ludicidade de Rondonópolis, Mato Grosso. Chama a atenção o fato de os pequenos tenderem a desmanchar os cantos temáticos, misturando os brinquedos, dentre outras ações pouco comuns ao olhar pedagógico. Em que pese tal percepção, o texto afirma que a natureza irracional e suprabiológica do jogo geralmente não é abordada pelas teorias educacionais, herdeiras da modernidade logocêntrica. Para contribuir com respostas teóricas ao problema, elaborou-se uma reflexão semiótica do brincar, demonstrando-se que os signos desta experiência não apresentam identidade fixa, fundamento de todo discurso racional. Com o percurso reflexivo, pretende-se ampliar as abordagens sobre a ludicidade, considerando sobretudo sua natureza estética e sígnica.

Palavras-chave: Brincar. Crianças. Estética. Signo.

\section{A reflection on the illogical component of the ludic - aesthetic experience ... mutant furniture in the arrangements of the living}

\footnotetext{
Abstract: The present work was inspired by the observation of four years old children, playing in a ludicity laboratory in Rondonópolis, Mato Grosso. It draws attention to the fact that the children tend to dismantle the thematic places, mixing the toys, among other uncommon actions, to the pedagogical look. In spite of such perception, the text affirms that the irrational and suprabiological nature of the game is not usually approached by educational theories, heirs of logocentric modernity. To contribute with theoretical answers to this problem, a semiotic reflection of play was elaborated, demonstrating that the signs of this experience do not present fixed identity, wich is the basis of the all rational discourse. Along the reflexive course, we intend to broaden the approaches to ludicity, considering above all its aesthetic and signic nature.
}

Keywords: Play. Children. Aesthetics. Sign. 
TREVISAN, Marlon Dantas. Uma reflexão sobre o componente ilógico do brincar - experiência estética... mobílias mutantes nos arranjos do vivido.

\section{Introdução}

O presente trabalho procura refletir sobre o brincar das crianças na Educação Infantil, destacando a tensão entre o que ciências da educação como a Psicologia e a Pedagogia entendem como natureza do brincar, em especial sua finalidade educativa, e o componente de ilogicidade que a criança, em exercícios de resistência, brincando, revela, apontando para contextos que por vezes pouco ou nada têm a ver com os discursos da racionalidade, tal como aparecem nas descrições epistemológicas. Recorrendo a Huizinga (1980), verificaremos que o caráter estético do jogo (aqui entendido como sinônimo do brincar em sua amplitude), sua natureza suprabiológica, não são abordados em geral pelas teorias. Com Foucault (1978) e a imagem da Nau dos Loucos, argumentaremos que a modernidade silenciou todas as formas de desrazão, para com isto afirmarmos que as descrições epistêmicas do brincar, guardadas as devidas proporções, fazem o mesmo com a experiência lúdica, varrendo daqueles discursos o componente de irracionalidade, inerente também aos animais. Em seguida, demonstramos que o jogo não é expressão da loucura, estabelecendo diferenças entre este e o cômico.

Procurando contribuir com respostas teóricas ao problema discutido, apresentamos uma abordagem semiótica do lúdico e sua natureza sígnica qualitativa. Com base na concepção fenomenológica de Peirce (2005), verificaremos que os signos do brincar, em especial os brinquedos, não apresentam identidade fixa, posto que são ícones, o que fere o princípio aristotélico de identidade e o da não contradição, fundamentos de todo enunciado racional. Com este percurso, pretendemos ampliar de algum modo a forma de abordarmos o brincar, considerando sua natureza estética e sígnica.

Na coordenação do "Laboratório de Ludicidade Profa. Dra. Soraiha Miranda de Lima", da Universidade Federal do Mato Grosso, Câmpus de Rondonópolis, ao observar dezenas de crianças de 4 anos oriundas da rede municipal de Educação Infantil brincando naquele espaço, no mês de novembro de 2017, percebemos a tendência de muitas delas em utilizarem diversos brinquedos, ao mesmo tempo, inserindo-se em situações de faz de conta as mais fragmentárias, misturando os cantos temáticos, tais como a cozinha, o mercadinho, o setor de carros, etc. Uma impressão perturbadora, dentre outras razões, porque o brinquedista busca ordenar a brinquedoteca, a partir de categorias inspiradas em situações do cotidiano (GIMENES; TEIXEIRA, 2011). Estas representações devem inserir os pequenos nos contextos da cultura, 
estimulando a imaginação, interações sociais, em síntese, o desenvolvimento integral (KISHIMOTO, 1997). Há uma preocupação no sentido de a brinquedoteca não se configurar como um espaço semelhante ao da sala de aula (SCHLEE, 2002). Isto poderá ocorrer, se o profissional ali responsável mantiver uma postura de excessiva severidade, distribuindo ordens, orientando pesadamente as brincadeiras. Não há, entretanto, como negar que todo espaço lúdico dessa natureza não sofra a ordenação pedagógica, por mais que tentemos romper com as lógicas da educação escolar. Em que pesem tais aspectos, no contexto da ludoteca, temos observado que as crianças rapidamente se libertam dos grilhões típicos das relações estabelecidas com os adultos na escola, lançando-se aos cantos e brinquedos, como sujeitos de sua experiência.

\section{O problema das concepções sobre o brincar}

Há um consenso sobre o brincar, no sentido de que este seja essencial ao desenvolvimento da criança (BROUGÈRE, 1998; KISHIMOTO, 2002; MONTESSORI, 1983; PIAGET, 1978; VALSINER, 2000; VYGOTSKY, 1998; WALLON, 2007). O que pretendemos apontar desta asserção é que, apesar de sua cristalizada importância, de modo a ter se tornado um lugar comum nos estudos sobre educação, poucos percebem que tal enunciado representa uma concepção eminentemente psicológica e pedagógica do brincar. Pensando com Foucault (1987), o que temos nos discursos da escolaridade moderna são regimes de controle, docilização e adestramento das crianças. Em grande medida, o estado da arte das pesquisas sobre o brincar nos apresenta um lugar, campo de forças de dimensões continentais, que expressa a colonização pela Pedagogia (assim como da Psicologia) da experiência lúdica. O exemplo mais drástico desta realidade nos parece ser a hegemônica visão instrumental sobre a brincadeira. Nesta direção, temos as mais diversas categorias criadas para a construção de brinquedos, como as que verificamos nos notórios contributos de Fröebel (HUGHES, 1925) e Montessori (1983). Não negamos aqui a importância desses autores para a literatura pedagógica. Seu legado muito contribuiu para a educação da infância. Há que se ressaltar, todavia, que ao descrevermos os brinquedos segundo categorias como valor funcional, experimental, de estruturação e de relação, como o fez o ICCP (International Council for Children's Pay), vamos eternizando o pressuposto de que o brincar apresenta necessariamente uma natureza educativa. Não condenamos tal conceito, porém afirmamos que uma percepção se perdeu no percurso da escola moderna: o brincar, a despeito de 
TREVISAN, Marlon Dantas. Uma reflexão sobre o componente ilógico do brincar - experiência estética... mobílias mutantes nos arranjos do vivido.

toda a tradição psicopedagógica que o descreve, traz em seu cerne o irracional. Território do pensamento que não coincide com o que consideramos as bases do conhecimento, ou mesmo daquilo que seja inteligível, em termos de linguagem.

Huizinga (1980) isto afirma, ponderando que o jogo transcende os contextos fisiológicos, psicológicos ou biológicos dos que o praticam. Mesmo com os animais, tal atividade vai além de um fenômeno de reflexo. Há algo inerente ao próprio jogo que não o remete a motivações externas a este, como comumente afirmam os teóricos.

No jogo existe alguma coisa "em jogo" que transcende as necessidades imediatas da vida e confere um sentido à ação. Todo jogo significa alguma coisa. Não se explica nada chamando "instinto" ao princípio ativo que constitui a essência do jogo, chamar-lhe "espírito" ou "vontade" seria dizer demasiado. Seja qual for a maneira como o considerem, o simples fato de o jogo encerrar um sentido implica a presença de um elemento não material em sua própria essência (HUIZINGA, 1980, p. 4).

O fato de haver no brincar um componente que foge em geral a uma descrição lógica, conforme nos revela o fragmento, nos parece suficiente para desconfiar de que a apropriação feita pela Pedagogia e outras ciências perdeu o melhor da festa. Sua maquinaria doutrinária e conceitual não lida bem com o que não se ajusta aos imperativos da racionalidade. Não por acaso teremos incontáveis sistemas de análise, hipóteses as mais diversas, em geral relacionando o brincar a algo, deslocando-o de si mesmo. Como refutar a afirmação vygotskyana de que os signos externos cumprem papel essencial no desenvolvimento da cognição infantil? (VYGOTSKY, 1998, p. 33). Os brinquedos assumiriam tal papel. Há também a percepção comum entre os teóricos de que toda hipótese ou mesmo definição resolve apenas problemas com relação às descrições anteriores, permanecendo as dificuldades (SPODEK; SARACHO, 1998). Não seria de espantar, se estamos em busca de um enquadramento identitário e racional para algo que nos foge, à medida que também pertence a outros terrenos da existência e da vida, a um contexto não material.

Huizinga (1980, p. 5) atentou a um aspecto especialmente soturno nas pesquisas sobre o jogo: em detrimento de metodologias quantitativas e experimentais, passam longe do caráter profundamente estético que uma brincadeira apresenta, perdendo com isto a característica fundamental desta, aquilo que a faz ser divertida: 
Por que razão o bebê grita de prazer? Por que motivo o jogador se deixa absorver inteiramente por sua paixão? Por que uma multidão imensa pode ser levada ao delírio por um jogo de futebol?" A intensidade do jogo e seu poder de fascinação não podem ser explicados por análises biológicas. E, contudo, é nessa intensidade, nessa fascinação, nessa capacidade de excitar que reside a própria essência e a característica essencial do jogo (HUIZINGA, 1980, p. 5).

Vemos que o componente mais essencial da experiência lúdica, aquilo que faz o bebê gargalhar, o cão fingir que morde o orelha do outro, uma torcida organizada delirar com um gol, todas estas e muitas outras experiências não são bem capturadas como objetos pela retina dos pesquisadores, embora estes possam fazer imensos esforços qualitativos. $\mathrm{O}$ aspecto do divertimento escapa copiosamente dos enunciados interpretativos com pretensões lógicas. Toda descrição científica esbarra nos termos de sua fundação.

O jogo inscreve-se em uma categoria "absolutamente primária da vida" (HUIZINGA, 1980, p. 5), uma totalidade que devemos ter cuidado ao avaliar e compreender. Uma prova de que a natureza do brincar transcende a vida humana e todo contexto racional é o fato de não se limitar à humanidade. Daí afirmarmos que o brincar esteja relacionado a qualquer grau de civilização se constitui outro disparate.

O discurso científico e normativo, todavia, não pode conceber o brincar como experiência irracional; do contrário, teríamos que admitir a porção de irracionalidade em nós. Como não somos isto, mas amamos o jogo, então precisamos descrever epistemologicamente o brincar. Nesse sentido, compreendemos os esforços das teorias: os discursos da ciência, enquadrando o jogo, incontáveis diagramas e categorizações, definindo brinquedos, brincadeiras e assim por diante. Tudo isto em conformidade com o projeto moderno, que não somente elegeu a razão e a experiência intelectual como o que temos de mais importante (JAY, 2009), como também segregou e perseguiu a desrazão, num longo processo de silenciamento desta (FOUCAULT, 1978).

\section{O brincar e a loucura}

Insistimos na percepção de que tem sido mais aceitável gnosiologicamente tratarmos o jogo como elemento de existência, se o descrevermos tal como o fazem as teorias do brincar, destaque ao percurso da cognição infantil, que tenderia à superação dos signos concretos, em direção aos abstratos e ao pensamento conceitual (PIAGET, 1978; VYGOTSKY, 1998). Destarte, 
TREVISAN, Marlon Dantas. Uma reflexão sobre o componente ilógico do brincar - experiência estética... mobílias mutantes nos arranjos do vivido.

signatários que somos das escolhas feitas na modernidade, deveremos mesmo banir das descrições que se pretendem rigorosas o que há de irracional e doentio no jogo.

Foucault (1978, p. 10) nos fornece uma paisagem do classicismo que, entre os séculos XV e XVII, revela a opção ocidental pela razão e a tentativa de expurgo daqueles que de algum modo a negaram, os loucos. Vale-nos muito dizer que todo indivíduo cujo arranjo existencial não correspondesse ao perfil do sujeito moderno, produtivo, adulto, branco, heterossexual, homem, pleno de faculdades cognoscitivas, pagaria, como até hoje observamos, um alto preço social, tal como o fazem as crianças, os artistas, estudantes, doentes, os que cometeram crimes e assim por diante.

Analisemos brevemente os portadores de doenças. No século XII, Inglaterra e Escócia contavam, apenas as duas, com duzentos e vinte leprosários. Foucault (1978) afirmara que as notórias doenças do período renascentista - lepra e, em seguida, a doença venérea - eram compreendidas pela medicina como relacionadas à loucura. Foram necessários, contudo, dois séculos para que o tratamento desta restaurasse os velhos e escabrosos ritos, tão comuns na Renascença. Este filósofo ilustra os modos como a cultura europeia lidou com a doença psiquiátrica: deslizando sobre os rios Reno, Jura, Besançon, ia a Nau dos Loucos, tão presente na literatura. Tivemos na embarcação Narrenschiff, de Sebastian Brant, texto publicado em 1497, um exemplo literário dos barcos que levavam os doentes psiquiátricos de cidade em cidade. Quando chegavam a uma delas, eram imediatamente expulsos, ou ainda entregues a grupos de mercadores e peregrinos. Um dos países que frequentemente agia deste modo era a Alemanha da primeira metade do século XV. O filósofo pondera que, apesar de ser uma prática comum, os loucos não eram banidos de modo sistemático das cidades. Isto ocorria mais com os estrangeiros.

Compreende-se melhor agora a curiosa sobrecarga que afeta a navegação dos loucos e que lhe dá sem dúvida seu prestígio. Por um lado, não se deve reduzir a parte de uma eficácia prática incontestável: confiar o louco aos marinheiros é com certeza evitar que ele ficasse vagando indefinidamente entre os muros da cidade, é ter a certeza de que ele irá para longe, é torna-lo prisioneiro de sua própria partida. Mas a isso a água acrescenta a massa obscura de seus próprios valores: ela leva embora, mas faz mais que isso, ela purifica. Além do mais, a navegação entrega o homem à incerteza da sorte: nela, cada um é confiado a seu próprio destino, todo embarque é, potencialmente, o último. É para o outro mundo que parte o louco em sua barca louca; é do outro mundo que ele chega quando desembarca (FOUCAULT, 1978, p. 17). 
Nessa passagem de inegável poeticidade, o filósofo sugere que os ritos de outrora, quando envolviam a lepra e posteriormente a doença venérea, desta feita se voltam aos loucos. Temos nisto diversos procedimentos sociais: banimento imediato das cidades, aprisionamento, purificação, despedidas e o convite à morte.

\section{Barcos fantasmas navegam sobre os discursos da racionalidade pedagógica}

Poderíamos ir adiante com relação ao tratamento da loucura, descrevendo as instituições hospitalares (hospícios), a medicalização dos transtornos, todavia nosso intento neste trabalho, reafirmamos, consiste em demonstrar que as ciências da educação sempre abordaram o brincar, a partir de arcabouços cartesianos, desconsiderando em geral seu componente de irracionalidade. Indagamos, em que pese o desconforto que isto possa causar: até que ponto aqueles ritos voltados para a loucura, no sentido de expurgá-la, puni-la, purificá-la, enfim, curá-la, em certa medida não alcançaram a superfície dos livros sobre educação? Não reproduziriam estes, com a obstinada busca pelo rigor, a herança do classicismo, o sonho iluminista? Será que não mais navegam "Narrenschiffs" sobre os gélidos lagos das epistemes? Para ficarmos com um exemplo disto: a afirmação de que a brincadeira estaria intimamente relacionada à construção simbólica, uma vez que, no faz-de-conta, a criança representa ações, pessoas e objetos, expandindo sua compreensão de mundo (PIAGET, 1978). Indagar-se-ia aqui: de que modo um enunciado de tal importância aos estudos da infância confirmaria a negação da desrazão? A nosso ver, pelo simples fato de abordar a atividade lúdica como operadora sígnica do desenvolvimento das faculdades psicológicas descritas como superiores (VYGOTSKY, 1998), não fazendo muitas referências ao componente ilógico do brincar, aquilo que faz as crianças bagunçarem a brinquedoteca, o que torna um pequeno de quatro anos super-herói, cozinheiro e motorista de caminhão, ao mesmo tempo. Do ponto de vista psicopedagógico, evidentemente que podemos ler essa dinâmica fragmentária, como se a criança estivesse se lançando à sua cultura, apreendendo, ressignificando papeis, e assim por diante, tal qual descrevem de modo inequívoco as teorias. Reafirmamos, todavia, que algo nos escapa, da ordem quiçá de uma pré-linguagem. Não há muito espaço nas teorias do brincar para o homo ludens (HUIZINGA, 1980), em especial, à descrição daquilo que torna os animais algo maior do que sua natureza aprisionada (LISPECTOR, 1999), e que não seria da ordem do instinto. 
Vale-nos ponderar que o jogo não é uma expressão da loucura. Se isto afirmarmos, cairemos na mesma armadilha que os teóricos em geral caíram: a de associar o brincar a outra realidade que não o próprio. Para maior clareza, convém-nos discriminar o jogo do cômico. Este, segundo Huizinga (1980), apresenta afinidades com o riso, uma vez que o provoca, mas a relação mantida entre o cômico e o jogo seria absolutamente secundária. O jogo não apresenta necessariamente a característica de comicidade, se o analisarmos em si mesmo. A loucura se relacionaria ao cômico. Uma produção dramaturgística, como a comédia, ou a arte circense do palhaço são formas artísticas que não se classificam como jogos. É possível afirmar que o cômico se aproxima da loucura (inverso da razão), a partir de análises que consideram polaridades como verdade e falsidade, realidade e fantasia, mal e bem, razão e desrazão, assim por diante. Com relação ao jogo, afirmou Huizinga, torna-se impossível tal enquadramento, sequer podemos atribuir-lhe função moral (HUIZINGA, 1980), a despeito das doutrinas do brincar, unânimes em afirmar que o mesmo teria, dentre outras funções, a capacidade (inegável) de ensinar regras de conduta às crianças (VYGOTSKY, 1998). O jogo está para muito além da moralidade.

Ratificamos: em que pese o componente irracional do brincar, não podemos considerá-lo expressão da loucura, tal como faríamos com o cômico. A dimensão do homo ludens aproxima a brincadeira da experiência estética, todavia não devemos necessariamente estabelecer tal relação. Nem todo jogo supõe uma experiência com a beleza, o ritmo, a harmonia, ponderou Huizinga (1980), embora haja firmes laços que unam o brincar à estética. De todas as aproximações, esta seria a menos arbitrária, sobretudo pelo que há de imponderável, plástico, inenarrável nas vivências estéticas e lúdicas. Neste sentido, lembramo-nos dos jogos pedagógicos de matemática ou escrita, que cumprem brilhantemente sua função educativa, mas pouco guardam do componente de diversão que a experiência lúdica genuína proporciona, tal como a emoção de fazermos uma cesta no basquetebol, ou a primeira onda domada por um surfista.

\section{O brincar sob a retina da semiótica}

Em busca de uma abordagem que sinalize para o terreno daquilo que Huizinga (1980) caracterizou como irracional, buscamos em Peirce (2005) e sua teoria sígnica, a compreensão de que o brincar seria uma experiência sobretudo fenomenológica e qualitativa. Este filósofo descreveu a experiência de viver, circunscrita a três dimensões: primeiridade - aquilo que nos 
passa tal como é, sem referência a outra coisa $(\mathrm{CP}, 2.220)^{1}$; algo que primeiro nos ocorre, de natureza potencial, no terreno apenas das possibilidades de representação, um fato bruto. Nessa dimensão, os signos são ícones - estruturas que se parecem com os objetos representados, exemplo: uma miniatura de panela, na brinquedoteca; secundidade - aquilo que é, ou que nos passa, marcado pela relação entre dois seres ou eventos, assim como pelo contexto de existência que se configura. Temos nessa dimensão fenomenológica a experiência também do conflito, bem como uma relação de causa e consequência, na transição do que era qualitativo e apenas possível, para o existente. Na dimensão da secundidade, os signos são índices, exemplo: o choro de criança gravado e instalado no peito em uma boneca; terceiridade é o que existe e se generalizou, relacionando reciprocamente um segundo e um terceiro contexto fenomenológicos $(\mathrm{CP}, 1.86)$. Eis o plano da mediação, da lei, território do pensamento conceitual. Os brinquedos com regras seriam exemplos de signos de terceiridade. Os signos desta dimensão foram caracterizados como símbolos.

Após estas considerações acerca da semiose do brincar, afirmamos aqui que este, por sempre simular a vida, constitui-se integralmente uma experiência icônica e de primeiridade, cujos signos são naturalmente degenerados - aqueles que configuram apenas possibilidades de representarem objetos. Esta característica é que nos permite aproximar a abordagem de Huizinga do brincar (natureza irracional) à concepção de primeiridade de Peirce. Prova maior disto nos parece ser o fato de que a criança, quando brinca, faz de seu brinquedo o que quiser, entregue à situação imaginária (VYGOTSKY, 1998, p. 127). Embora haja certo lugar comum, de que ícone seja sinônimo de imagem, o excerto a seguir nos revela a abrangência do conceito peirceano: "Qualquer coisa, seja uma qualidade, um existente individual ou uma lei, é ícone de qualquer coisa, na medida em que for semelhante a essa coisa e utilizado como um seu signo" (CP, 3.247). Há algo de profundamente democrático em se afirmar que qualquer coisa poderá ser um signo icônico de qualquer outra coisa. O que, em certa medida, contraria o princípio aristotélico de identidade e mesmo o de não-contradição, sobre os quais se assentam os discursos da razão. Os brinquedos são signos sem identidade fixa; um cabo de vassoura pode se tornar uma espingarda ou um cavalo. Tal mobilidade, em termos de linguagem, por ora nos basta para compreender o componente irracional da experiência lúdica.

\footnotetext{
${ }^{1}$ Em respeito aos semioticistas peirceanos, usaremos daqui por diante a seguinte forma para citar Peirce (2005): CP 2.220 - Colected Papers, Livro 2, Capítulo 220.
} 
Em busca de maior rigor lógico, Peirce criou uma tricotomia para os ícones, ou melhor, hipoícones (para discriminá-los dos ícones puros). Para estes, Peirce criou a tríade: imagem (primeiridade) / diagrama (secundidade) / metáfora (terceiridade). Imagens são hipoícones que se assemelham, de algum modo, aos objetos expressos. Exemplo: foto de um urso polar. Diagramas são signos cujas estruturas apresentam relações de contiguidade com as estruturas dos objetos representados. Exemplos de diagrama: Jogos de quebra-cabeças. Metáforas são hipoícones que revelam em terceiridade uma relação de paralelismo com o objeto, assim como enunciam conceitos e leis acerca do mesmo, podendo gerar símbolos, declarou Peirce, na medida em que põem em analogia conceitos diferentes, desde que estruturalmente contíguos (CP, 2.222). Exemplo: O jogo de xadrez e os enfrentamentos do cotidiano. É possível afirmarmos que as metáforas também apresentam, além de imagens, uma natureza diagramática, no que se referem ao objeto.

Vale-nos ponderar que não existe possibilidade de que comuniquemos algo sem a mediação dir eta ou indireta de ícones. Todo signo mental assertivo os carrega, ou será explicado por estes (CP, 4.278). Também afirmamos com Peirce que não há pensamento sem signos, mesmo no mundo animal. A experiência lúdica, por mais que carregue em si uma característica de irracionalidade, está atrelada ao fato de ser fruto de pensamento em ação, portanto, trata-se de uma experiência com signos. Mais do que isto, insere-se em um contexto de iconicidade, conforme já afirmamos, e que tem como fundamento a experiência estética e, por que não afirmar, poética. Contexto de possibilidades abertas, livres ainda do governo pedagógico ou moral. Os brinquedos assumem a índole de metáforas visuais que podem submergir, desintegrarse, ressurgir nos perceptos (planos de percepção), transformar-se em novos enunciados interpretativos, mutantes.

As crianças, ao brincarem, vivem experiências sobretudo em primeiridade, uma vez que sabem que a brincadeira não é realidade, portanto não adentram genuinamente a secundidade (categoria dos índices e da certeza). Isto nos permite afirmar que, dispondo-se de signos qualitativos (brinquedos), possibilidades de representação e expressão, lançam-se ao imponderável da dimensão estética, numa enérgica bagunça, em vigorosos exercícios da imaginação. A percepção de a criança saber que lida com uma realidade falsa é comum aos teóricos (BROUGÈRE, 1998; PIAGET, 1978; VYGOTSKY, 1998). 
TREVISAN, Marlon Dantas. Uma reflexão sobre o componente ilógico do brincar - experiência estética... mobílias mutantes nos arranjos do vivido.

Notemos a proximidade que há entre a categoria fenomenológica de primeiridade peirceana e o que afirma Huizinga (1980) acerca do lúdico:

A concepção que apresentamos nas páginas que se seguem é que a cultura surge sob a forma de jogo, que ela é, desde seus primeiros passos como que "jogada". Mesmo as atividades que visam a satisfação das necessidades vitais, como por exemplo a caça, tendem a assumir nas sociedades primitivas uma forma lúdica. A vida social reveste-se de formas suprabiológicas, que lhe conferem uma dignidade superior sob a forma de jogo, e é através deste último que a sociedade exprime sua interpretação da vida e do mundo. Não queremos com isto dizer que o jogo se transforma em cultura, e sim que em suas fases mais primitivas a cultura possui um caráter lúdico, que ela se processa segundo as formas e no ambiente do jogo (p. 53).

O autor enfatiza que o jogo não dá origem à cultura, mas que esta surge de modo lúdico. Tal asserção apresenta relações de contiguidade com o que Peirce afirmou em sua fenomenologia, no que tange às experiências qualitativas e potenciais, expressas por ícones e qualissignos - pré-signos - que engendram códigos abertos, que operam no terreno amplo das possibilidades de representação do vivido. Pensamos que possa residir neste aspecto o algo de irracional, de que tratamos neste escrito, e que também é experimentado pelos animais. Irracional porque não percorreria necessariamente a semiose - processamento de signos - de maneira a atingir o símbolo verbal e consequentemente o discurso dos conceitos, como descreve a tradição teórica sobre o brincar. O pavão, ao deslumbrar a fêmea com sua plumagem azul argênteo, vive uma experiência estética, sensorial, sem pretensões outras que não ser admirado e seduzir. Muito embora o processamento dos signos lúdicos tenda no fim das contas (no caso dos humanos) a caminhar para o discurso conceitual, isto pouco importa à criança, que busca a emoção do divertimento.

\section{Considerações finais}

Esta reflexão procurou apontar os problemas que as ciências da Educação enfrentam ao descrever o brincar, sendo estas as herdeiras de uma tradição iluminista consolidada na modernidade, que desconsidera e segrega toda manifestação que não se enquadre nos cânones da racionalidade. Em termos pedagógicos, isto trouxe duas consequências especialmente nocivas à criança, em relação às concepções sobre o lúdico: a brincadeira sendo valorizada apenas em sua função instrumental e o desprezo ao brincar livre, entendido como sinônimo de atividade não educativa. Lamentavelmente, estas compreensões são cristalizadas, de difícil superação, 
sobretudo em relação aos professores da Educação Infantil. Esperamos, com as análises aqui empreendidas, que os mesmos possam refletir sobre os limites discursivos das ciências pedagógicas, em especial aquelas voltados ao brincar, em exercícios que possibilitem criarmos caminhos de fuga, fraturas nos enunciados destinados ao disciplinamento e docilização dos pequenos corpos. Quem sabe a compreensão do componente de ilogicidade - suprarrealidade, múltipla identidade, diversão - do brincar possa ser reconsiderado nas práticas pedagógicas, sem que estas reflitam a colonização do que para a vida inteligente é essencial: o jogo.

\section{Referências}

BRANT, Sebastian. Das Narrenschiff. 1497. Monografie.

BROUGÈRE, Gilles. Brinquedo e cultura. São Paulo: Cortez, 1998.

FOUCAULT, Michel. História da loucura na idade clássica. São Paulo: Perspectiva, 1978.

FOUCAULT, Michel. Vigiar e punir. Petrópolis: Vozes, 1987.

GIMENES, Beatriz Picolo; TEIXEIRA, Sirlândia Reis de Oliveira. Brinquedoteca: manual em educação e saúde. São Paulo: Cortez, 2011.

HUGHES, James Langston. La pedagogia de Froebel. Madrid: Daniel Jorro, 1925.

HUIZINGA, Johan. Homo Ludens: o jogo como elemento da cultura. São Paulo: Perspectiva, 1980.

JAY, Martin. Cantos de experiencia. Variaciones modernas sobre un tema universal. Buenos Aires: Paidós, 2009.

KISHIMOTO, Tizuko Morchida. Construir brinquedos e organizar espaços de brincadeiras, como parte integrante do projeto pedagógico. São Paulo: LABRIMP/FEUSP/FUND.ORSA, 1997.

KISHIMOTO, Tizuko Morchida. O brincar e suas teorias. São Paulo: Pioneira-Thomson Learning, 2002.

LISPECTOR, Clarice. Tentação. In: LISPECTOR, Clarice. A legião estrangeira: contos. Rio de Janeiro: Rocco, 1999.

MONTESSORI, Maria. A criança. Rio de Janeiro: Nórdica, 1983.

PEIRCE, Charles Sanders. Semiótica. São Paulo: Perspectiva, 2005.

PIAGET, Jean. A formação do símbolo: imitação, jogo e sonho, imagem e representação. Rio de Janeiro: Zahar, 1978.

SCHLEE, Andrey Rosenthal. Brinquedoteca: uma alternativa espacial. In: SANTOS, Santa Marli Pires dos (Org.). Brinquedoteca: a criança, o adulto e o lúdico. Petrópolis: Vozes, 2002.

SPODEK, Bernard; SARACHO, Olivia Natividad. Ensinando crianças de três a oito anos. Porto Alegre: Artmed, 1998.

VALSINER, Jaan. Culture and human development. Londres: Sage, 2000.

VYGOTSKY, Lev Semenovitch. A formação social da mente. São Paulo: Martins Fontes, 1998. 
TREVISAN, Marlon Dantas. Uma reflexão sobre o componente ilógico do brincar - experiência estética... mobílias mutantes nos arranjos do vivido.

WALLON, Henri. A evolução psicológica da criança. São Paulo: Martins Fontes, 2007.

\author{
Marlon Dantas Trevisan \\ Universidade Federal de Mato Grosso | Departamento de Educação \\ - Instituto de Ciências Humanas e Sociais (ICHS) - Programa de \\ Pós-Graduação em Educação (PPGEdu) \\ Rondonópolis | MT | Brasil. Contato: marloneanela@uol.com.br \\ ORCID 0000-0002-5822-0677
}

Artigo recebido em: 22 nov. 2017 e aprovado em: 10 jul. 2018. 